\title{
Diamide Derivatives and Cycloartanes from the Leaves of Aglaia elliptica
}

\author{
Akira Inada,,$* a$ Takako Sorano, ${ }^{a}$ Hiroko Murata,${ }^{a}$ Yuka Inatomi,${ }^{a}$ Dedy Darnaedi, ${ }^{b}$ and \\ Tsutomu NAKANISHI ${ }^{a}$ \\ Faculty of Pharmaceutical Sciences, Setsunan University, ${ }^{a} 45-1$ Nagaotoge-cho, Hirakata, Osaka 573-0101, Japan and \\ Herbarium Bogoriense, ${ }^{b}$ Jalan Ir, H. Juanda, Bogor 16122, Indonesia. $\quad$ Received April 23, 2001; accepted June 9, 2001
}

\begin{abstract}
Chemical examination of the leaves of Aglaia elliptica led to the isolation of two new diamides, 10-O-acetylaglain B (1) and 4-epiaglain A (2), two known diamides, aglain A (3) and odorine (4), and three known cycloartanes (5-7). The structures of 1 and 2 were elucidated by interpretation of the spectral data.
\end{abstract}

Key words Aglaia elliptica; diamide; 10- $O$-acetylaglain B; 4-epiaglain A; aglain A; Meliaceae

The genus Aglaia (Meliaceae) consists of about 130 species that are dioecious trees or shrubs and the plants of this genus are mainly distributed in tropical and subtropical regions. Several novel amides containing a cyclopenta$[b c]$ benzopyran moiety (=aglain-type) and a cyclopenta$[b]$ benzofuran moiety (=rocaglamide-type) as the acid part have been characterized from this genus, ${ }^{1-20)}$ some of which were shown to exhibit cytotoxic ${ }^{1,3,5,7,10,19,20)}$ insectici$\mathrm{dal}^{2,6,8,9,11-15,17)}$ and antifungal ${ }^{4)}$ activities. In our series of studies of this genus, ${ }^{16)}$ we have investigated the constituents of the leaves of Aglaia elliptica B1. Rocaglamide derivatives from the fruits ${ }^{9)}$ and rocaglamide derivatives and dammaranes from the stems and fruits of this plant ${ }^{10)}$ have already been characterized. However, to our knowledge there have been no phytochemical reports on the leaves.

Repeated column chromatography and HPLC separation of a $\mathrm{MeOH}$ extract of the leaves resulted in the isolation of two new aglain derivatives, $10-O$-acetylaglain $\mathrm{B}(\mathbf{1})$ and 4 epiaglain A (2), two known diamides $(\mathbf{3}, \mathbf{4})$, and three known cycloartanes (5-7). Compounds 3 and 4 were identified as aglain $\mathrm{A}^{5)}$ and aminopyrrolidine-diamide, odorine, ${ }^{21,22)}$ by a combination of spectroscopic analyses and comparisons with reported data. Compounds 5-7 were known cycloartanes ${ }^{23,24)}$ previously isolated from Aglaia harmsiana and identified by direct comparisons with authentic samples. Compound 1, $[\alpha]_{\mathrm{D}}+20.4^{\circ}(\mathrm{MeOH})$, gave a molecular ion peak $\left(\mathrm{M}^{+}\right)$of $\mathrm{C}_{38} \mathrm{H}_{44} \mathrm{~N}_{2} \mathrm{O}_{9}$ by high resolution (HR)-electron ionization (EI)-MS and showed absorptions at 1750 (ester), 1680, 1620 (amide), and $1595 \mathrm{~cm}^{-1}$ (benzene ring) in the IR spectrum. The ${ }^{1} \mathrm{H}-\mathrm{NMR}$ spectrum of $\mathbf{1}$ (Table 1) analyzed with the aid of two-dimensional (2D)-NMR studies $\left[{ }^{1} \mathrm{H}-{ }^{1} \mathrm{H}\right.$ and ${ }^{13} \mathrm{C}-{ }^{1} \mathrm{H}$ shift-correlated spectroscopy (COSY), and nuclear Overhauser enhancement spectroscopy (NOESY) experiments] indicated the presence of three methoxy methyls $(\delta 3.76,3.78,3.91)$, an acetoxyl methyl $(\delta 2.08)$, three methines $[\delta 4.11(\mathrm{~d}, J=5.7 \mathrm{~Hz}), 4.87(\mathrm{~d}, J=5.7 \mathrm{~Hz}), 4.78(\mathrm{~s}-$ like)], and 11 benzene protons comprised of two meta-coupled protons of a benzene ring, four protons of a $p$-disubstituted benzene ring, and five protons of a monosubstituted benzene ring. In addition, a 2-amino-pyrrolidine ring and aliphatic side chain moiety reminiscent of those reported for odorine (4) were observed. ${ }^{21,22)}$ In addition to these units, the

Table 1. ${ }^{1} \mathrm{H}-\mathrm{NMR}$ Spectral Data of $\mathbf{1}-\mathbf{3}$ in $\mathrm{CD}_{3} \mathrm{OD}(600 \mathrm{MHz})^{a)}$

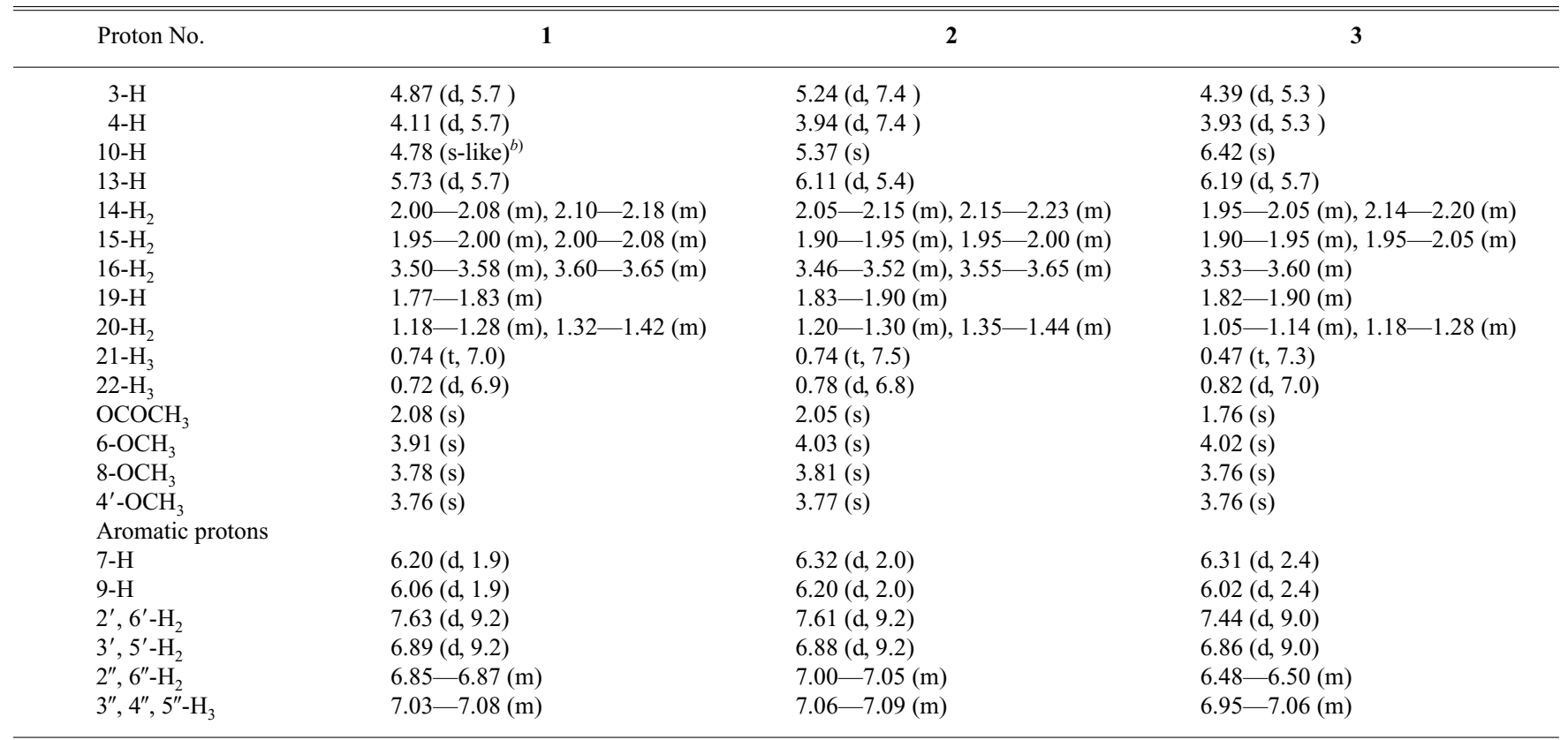

a) Chemical shifts are in $\delta$-values from internal tetramethylsilane (TMS) and are followed by multiplicities and $J$-values (in Hz). $b$ ) A small long-range coupling (Wshaped) between $4 \alpha-\mathrm{H}$ was further observed in the COSY spectrum. 
Table 2. ${ }^{13} \mathrm{C}$-NMR Spectral Data of $\mathbf{1}-\mathbf{3}$ in $\mathrm{CD}_{3} \mathrm{OD}(150 \mathrm{MHz}, \delta$-Values $)$

\begin{tabular}{|c|c|c|c|c|c|c|c|}
\hline Carbon No. & 1 & 2 & 3 & Carbon No. & 1 & 2 & 3 \\
\hline $1 \mathrm{a}$ & 154.8 & 154.8 & 155.6 & 20 & 28.3 & 28.3 & 27.9 \\
\hline 2 & 92.0 & 89.5 & 86.8 & 21 & 12.1 & 12.2 & 12.1 \\
\hline 3 & 55.1 & 55.4 & 56.6 & 22 & 17.5 & 17.6 & 17.3 \\
\hline 4 & 61.6 & 62.2 & 58.2 & $1^{\prime}$ & 131.0 & 130.2 & 131.9 \\
\hline 5 & 84.8 & 83.9 & 80.1 & $2^{\prime}, 6^{\prime}$ & 129.0 & 128.9 & 128.4 \\
\hline $5 a$ & 109.8 & 112.2 & 108.5 & $3^{\prime}, 5^{\prime}$ & 114.1 & 114.3 & 114.3 \\
\hline 6 & 157.6 & 157.7 & 159.4 & $4^{\prime}$ & 160.7 & 160.9 & 160.6 \\
\hline 7 & 93.3 & 93.8 & 93.5 & $1^{\prime \prime}$ & 138.2 & 138.8 & 137.6 \\
\hline 8 & 162.7 & 162.8 & 162.6 & $2^{\prime \prime}, 6^{\prime \prime}$ & 130.7 & 130.9 & 130.6 \\
\hline 9 & 94.6 & 95.3 & 94.8 & $3^{\prime \prime}, 5^{\prime \prime}$ & 129.8 & 129.5 & 128.8 \\
\hline 10 & 81.2 & 80.9 & 74.8 & $4^{\prime \prime}$ & 128.0 & 127.8 & 127.9 \\
\hline 11 & 173.7 & 170.7 & 172.5 & $6-\mathrm{OCH}_{3}$ & 56.3 & 56.6 & 56.8 \\
\hline 13 & 65.8 & 65.5 & 65.2 & $8-\mathrm{OCH}_{3}$ & 56.0 & 56.0 & 56.0 \\
\hline 14 & 35.2 & 35.0 & 34.8 & $4^{\prime}-\mathrm{OCH}_{3}$ & 55.7 & 55.7 & 55.7 \\
\hline 15 & 22.3 & 22.0 & 22.2 & $\mathrm{OCOCH}_{3}$ & 170.4 & 171.7 & 171.6 \\
\hline 16 & 47.8 & 47.3 & 47.3 & & 21.2 & 22.0 & 20.7 \\
\hline 18 & 178.0 & 178.0 & 178.2 & & & & \\
\hline 19 & 43.0 & 43.1 & 43.2 & & & & \\
\hline
\end{tabular}

${ }^{13} \mathrm{C}-\mathrm{NMR}$ spectrum of $\mathbf{1}$ (Table 2 ) analyzed with the aid of ${ }^{13} \mathrm{C}-{ }^{1} \mathrm{H}-\mathrm{COSY}$ and heteronuclear multiple-bond correlation spectroscopy (HMBC) experiments exhibited signals due to two amide carbonyl carbons ( $\delta 173.7,178.0)$, an ester carbonyl carbon ( $\delta 170.4)$, and two aliphatic quaternary carbons bearing an oxygen atom $(\delta 84.8,92.0)$. The results indicate that compound $\mathbf{1}$ is an aglain derivative. ${ }^{5,12,13,16,18-20)}$

Among them, the spectral data of $\mathbf{1}$ were very similar to those of aglain $\mathrm{B}(\mathbf{8}){ }^{5)}$ However the signal due to a $10-\mathrm{OH}$ in $\mathbf{8}$ was absent in $\mathbf{1}$ and this signal was replaced with an acetoxyl group $\left(\delta_{\mathrm{H}} 2.08 ; \delta_{\mathrm{C}} 21.2,170.4\right)$. Accordingly, the $10-\mathrm{H}$ of $8(\delta 4.10)^{5)}$ was downfield-shifted to $\delta 4.78$ in $\mathbf{1}$. This substitution was also supported by the selective NOESY correlations, as shown in Fig. 1. That is, compound $\mathbf{1}$ gave significant cross peaks between $10-\mathrm{H} / 2^{\prime}, 6^{\prime}-\mathrm{H}_{2}$, between $3-\mathrm{H} / 2^{\prime}, 6^{\prime}$ $\mathrm{H}_{2}, 2^{\prime \prime}, 6^{\prime \prime}-\mathrm{H}_{2}$, and between $4-\mathrm{H} / 2^{\prime \prime}, 6^{\prime \prime}-\mathrm{H}_{2}$. Thus the relative stereochemistry of $10-\mathrm{H}, 3-\mathrm{H}$, and $4-\mathrm{H}$ is as shown in Fig. 2 . $^{25)}$

Finally, the unambiguous structure of $\mathbf{1}$ was established from the following $\mathrm{HMBC}$ experiments and significant correlation peaks between $3-\mathrm{H} / \mathrm{C}-2, \mathrm{C}-4, \mathrm{C}-5, \mathrm{C}-1^{\prime \prime}$ and between 4-H/C-3, C-5, C-5a, C-10, C-1" were observed. $^{26)}$ In addition, correlation peaks between $3-\mathrm{H} / \mathrm{C}-1^{\prime}$, and between $4-$ $\mathrm{H} / \mathrm{C}-11$ indicated the connectivities of $\mathrm{C}-3$ to the monosubstituted benzene ring and of $\mathrm{C}-4$ to the $\mathrm{C}-11$ amide carbonyl carbon. Based on the evidence, the structure of $\mathbf{1}$ is as shown in Fig. 2.

4-Epiaglain $\mathrm{A}(2),[\alpha]_{\mathrm{D}}-1.0^{\circ}\left(\mathrm{CHCl}_{3}\right)$, had the same molecular formula $\left(\mathrm{C}_{38} \mathrm{H}_{44} \mathrm{~N}_{2} \mathrm{O}_{9}\right)$ as 1 based on HR-EI-MS. The IR spectrum of 2 showed absorptions at 1750 (ester), 1660, 1620 (amide), and $1595 \mathrm{~cm}^{-1}$ (benzene ring). The ${ }^{1} \mathrm{H}-\mathrm{NMR}$ spectrum of 2 (Table 1) analyzed with the aid of 2D-NMR studies showed the presence of the same functional groups and moiety as in $\mathbf{1}$. The ${ }^{13} \mathrm{C}$-NMR spectrum of $\mathbf{2}$ (Table 2 ) exhibited signals due to two amide carbonyl carbons $(\delta$ $170.7,178.0)$ and an ester carbonyl carbon $(\delta 171.7)$, suggesting that 2 is also an aglain derivative..$^{5,12,13,16,18-20)}$ The ${ }^{1}$ H-NMR-spectral data of $\mathbf{2}$ were similar to those of aglain A (3). ${ }^{5)}$ However, the chemical shifts and $J$-values of the signals due to $3-\mathrm{H}(\mathbf{2}, \delta 5.24, \mathrm{~d}, J=7.4 \mathrm{~Hz} ; \mathbf{3}, \delta 4.39, \mathrm{~d}, J=5.3 \mathrm{~Hz})$ and $4-\mathrm{H}(\mathbf{2}, \delta 3.94, \mathrm{~d}, J=7.4 \mathrm{~Hz} ; \mathbf{3}, \delta 3.93, \mathrm{~d}, J=5.3 \mathrm{~Hz})$ are
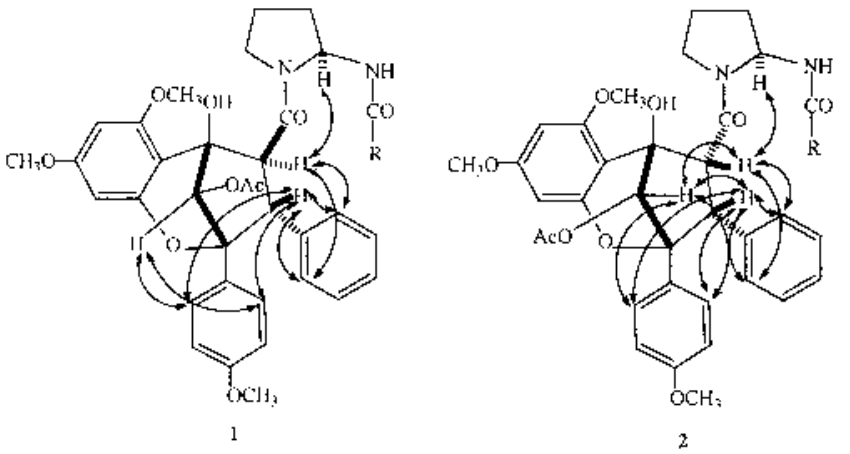

Fig. 1. Selected NOESY Correlations of $\mathbf{1}$ and $\mathbf{2}$

obviously different to each other. The results indicate that compound $\mathbf{2}$ is a stereoisomer of $\mathbf{3}$.

Dreiding model inspections suggested the presence of either $3 \beta-\mathrm{H} / 4 \beta-\mathrm{H}$ or $3 \alpha-\mathrm{H} / 4 \alpha-\mathrm{H}$ relative stereochemistry in 2 instead of the $3 \beta-\mathrm{H} / 4 \alpha-\mathrm{H}$ relative stereochemistry in $\mathbf{3}$ (and also in 1). The $3 \beta-\mathrm{H} / 4 \beta$-H stereochemistry in 2 was determined as follows. In the NOESY experiments as shown in Fig. 1, a methine proton ascribable to $10-\mathrm{H}(\delta 5.37)$ showed significant correlations with both $3-\mathrm{H}$ and $4-\mathrm{H}$. In addition, correlation peaks between $10-\mathrm{H} / 2^{\prime}, 6^{\prime}-\mathrm{H}_{2}$, between $3-\mathrm{H} / 2^{\prime}$, $6^{\prime}-\mathrm{H}_{2}, 2^{\prime \prime}, 6^{\prime \prime}-\mathrm{H}_{2}$, and between $4-\mathrm{H} / 2^{\prime \prime}, 6^{\prime \prime}-\mathrm{H}_{2}$, were observed. Hence the relative stereochemistry of $10-\mathrm{H}, 3-\mathrm{H}$, and $4-\mathrm{H}$ of $\mathbf{2}$ is as shown in Fig. 2. ${ }^{25}$ The final structure of $\mathbf{2}$ was established from the HMBC experiments, and $\mathbf{2}$ exhibited similar and significant correlation peaks to those observed in $1 .^{27)}$ Based on the evidence, the structure of 4-epiaglain A is $\mathbf{2}$. In accordance with the biogenetic hypothesis of aglain derivatives, ${ }^{5,12,13)}$ one supposed precursor, odorine $(4),{ }^{21,22)}$ was also isolated and identified from this plant.

\section{Experimental}

The IR spectra were recorded on a JASCO A-302 spectrophotometer. Optical rotations were measured on a JASCO-DIP-140 digital polarimeter. The EI-, FAB-, and HR-EI-MS were recorded on JEOL JMS-DX 300 and JMS700T spectrometers. The ${ }^{1} \mathrm{H}$ - and ${ }^{13} \mathrm{C}-\mathrm{NMR}$ spectra were recorded on a GEOMEGA 600 spectrometer (600 and $150 \mathrm{MHz}$, respectively), with $\mathrm{MeOH}-d_{4}$ as a solvent and tetramethylsilane (TMS) as an internal standard. HPLC was performed on a JAILC-908 instrument with JAIGEL-ODS-S343-15 and JAIGEL-GS310 columns with a differential refractometer. 

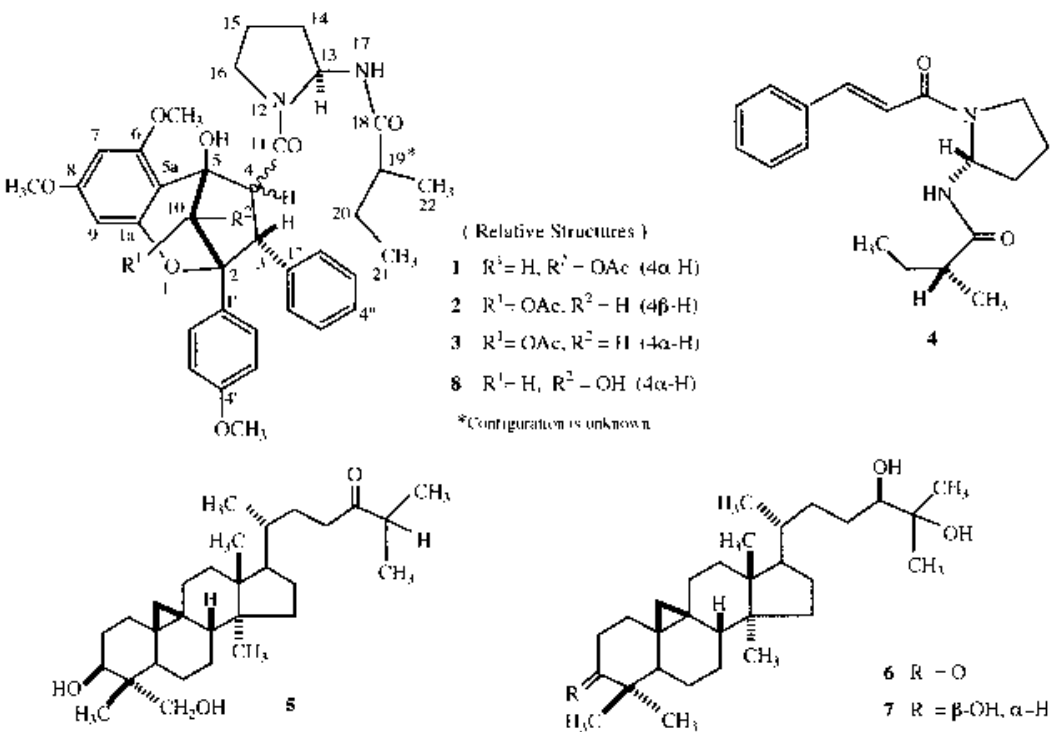

Fig. 2. Structures of Compounds $\mathbf{1}-\mathbf{8}$

Plant Material The leaves of A. elliptica B1. were harvested in 1993 at the Herbarium Bogoriense, Java, Indonesia, and voucher specimens have been deposited at the Herbarium of the Faculty of Pharmaceutical Sciences, Setsunan University.

Extraction and Isolation The dried leaves ( $395 \mathrm{~g})$ were extracted with $\mathrm{MeOH}$ and the solvent was evaporated. The $\mathrm{MeOH}$ extract $(39.0 \mathrm{~g})$ was suspended with $\mathrm{H}_{2} \mathrm{O}$ and the aqueous suspension was extracted in succession with hexane and EtOAc. The combined hexane and EtOAc extract $(19.0 \mathrm{~g})$ was chromatographed on silica gel with $\mathrm{CHCl}_{3}-\mathrm{MeOH}$ containing increasing $\mathrm{MeOH}$ concentrations. Each fraction containing 1-7, was further purified with repeated HPLC separation to afford $\mathbf{1}(10.1 \mathrm{mg}), \mathbf{2}(5.3 \mathrm{mg}), \mathbf{3}$ $(15.8 \mathrm{mg}){ }^{5)} 4(250 \mathrm{mg}){ }^{21,22)} \mathbf{5}(6.8 \mathrm{mg}){ }^{23)} \mathbf{6}(57 \mathrm{mg}),{ }^{23)}$ and $7(75 \mathrm{mg})^{24}$ along with $\beta$-sitosterol ( $25 \mathrm{mg}$ ) and $\beta$-sitosterol glucoside $(140 \mathrm{mg})$. Known compounds $(3-7)$ were identified by direct comparison with authentic samples or by comparisons of their spectral data.

10- $O$-Acetylaglain B (1): An amorphous powder; $[\alpha]_{\mathrm{D}}^{20}+20.4^{\circ}(c=0.83$, $\mathrm{MeOH})$; IR (KBr) cm ${ }^{-1}$ : 3370, 1750, 1680, 1620, 1595, 1520, 1150; EI- and HR-EI-MS: $m / z(\%) 672.3049\left(\mathrm{M}^{+}, \mathrm{C}_{38} \mathrm{H}_{44} \mathrm{~N}_{2} \mathrm{O}_{9}\right.$ requires $\left.672.3047,>1\right), 571$ (18), 442 (65), 313 (100), 200 (39), 131 (79), 73 (98) ; FAB-MS: $m / z 673$ $[\mathrm{M}+\mathrm{H}]^{+}, 695[\mathrm{M}+\mathrm{Na}]^{+} ;{ }^{1} \mathrm{H}-$ and ${ }^{13} \mathrm{C}-\mathrm{NMR}$ : Tables 1 and 2 , respectively.

4-Epiaglain A (2): An amorphous powder; $[\alpha]_{\mathrm{D}}^{20}-1.0^{\circ}\left(c=0.97, \mathrm{CHCl}_{3}\right)$; IR (KBr) cm $\mathrm{cm}^{-1}: 3450,1750,1660,1620,1595,1515,1150$; EI- and HR-EIMS: $m / z(\%) 672.3042\left(\mathrm{M}^{+}, \mathrm{C}_{38} \mathrm{H}_{44} \mathrm{~N}_{2} \mathrm{O}_{9}\right.$ requires 672.3047, >1), 571 (18), 442 (40), 313 (100), 200 (23), 131 (49), 73 (61); FAB-MS: $m / z 673$ $[\mathrm{M}+\mathrm{H}]^{+}, 695[\mathrm{M}+\mathrm{Na}]^{+} ;{ }^{1} \mathrm{H}-$ and ${ }^{13} \mathrm{C}-\mathrm{NMR}$ : Tables 1 and 2 , respectively.

Aglain A (3) ${ }^{5)}$ : An amorphous powder; ${ }^{1} \mathrm{H}$ - and ${ }^{13} \mathrm{C}-\mathrm{NMR}$ : Tables 1 and 2 , respectively.

Acknowledgments We are sincerely grateful to Dr. M. Nishi and Mr. M. Yamaguchi of Setsunan University for their measurement of the NMR and MS spectra. This study was supported in part by a Grant-in-Aid for Scientific Research (No.12672077) from the Ministry of Education, Science, Sports and Culture, Japan.

\section{References and Notes}

1) King M. L., Chiang C.-C., Ling H.-C., Fujita E., Ochiai M., McPhail A. T., J. Chem. Soc., Chem. Commun., 1982, 1150-1151.

2) Janprasert J., Satasook C., Sukumalanand P., Champagne D. E., Isman M. B., Wiriyachitra P., Towers G. H. N., Phytochemistry, 32, 67-69 (1993).

3) Ohse T., Ohba S., Yamamoto T., Koyano T., Umezawa K., J. Nat. Prod., 59, 650-652 (1996).

4) Fuzzati N., Dyatmiko W., Rahman A., Achmad F., Hostettmann K., Phytochemistry, 42, 1395-1398 (1996).

5) Dumontet V., Thoison O., Omobuwajo O. R., Martin M.-T., Perromat G., Chiaroni A., Riche C., Pais M., Sevenet T., Hadi A. H. A., Tetrahedron, 52, 6931-6942 (1996).

6) Güssregen B., Fuhr M., Nugroho B. W., Wray V., Witte L., Proksch P., Z. Naturforsch., 52c, 339-344 (1997).
7) Wu T.-S., Liou M.-J., Kuoh C.-S., Teng C.-M., Nagano T., Lee K.-H., J. Nat. Prod., 60, 606-608 (1997).

8) Nugroho B. W., Edrada R. A., Güssregen B., Wray V., Witte L., Proksch P., Phytochemistry, 44, 1455-1461 (1997).

9) Nugroho B. W., Güssregen B., Wray V., Witte L., Bringmann G., Proksch P., Phytochemistry, 45, 1579—1585 (1997).

10) Cui B., Chai H., Santisuk T., Reutrakul V., Farnworth N. R., Cordell G. A., Pezzuto J. M., Kinghorn A. D., Tetrahedron, 53, 17625-17632 (1997).

11) Brader G., Vajrodaya S., Greger H., Bacher M., Kalchhauser H., Hofer O., J. Nat. Prod., 61, 1482-1490 (1998).

12) Nugroho B. W., Edrada R. A., Wray V., Witte L., Bringmann G., Gehling M., Proksch P., Phytochemistry, 51, 367-376 (1999).

13) Bacher M., Hofer O., Brader G., Vajrodaya S., Greger H., Phytochemistry, 52, 253-263 (1999).

14) Chaidir, Hiort J., Nugroho B. W., Bohnenstengel F. I., Wray V., Witte L., Hung P. D., Kiet L. C., Sumaryono W., Proksch P., Phytochemistry, 52, 837-842 (1999).

15) Hiort J., Chaidir., Bohnenstengel F. I., Nugroho B. W., Schneider C., Wray V., Witte L., Hung P. D., Kiet L. C., Proksch P., J. Nat. Prod., 62, $1632-1635$ (1999).

16) Inada A., Shono K., Murata H., Inatomi Y., Darnaedi D., Nakanishi T., Phytochemistry, 53, 1091-1095 (2000).

17) Schneider C., Bohnenstengel F. I., Nugroho B. W., Wray V., Witte L., Hung P. D., Kiet L. C., Proksch P., Phytochemistry, 54, 731-736 (2000).

18) Puripattanavong J., Weber S., Brecht V., Frahm A. W., Planta Med., 66, $740-745(2000)$.

19) Xu Y.-J., Wu X.-H., Tan B. K. H., Lai Y.-H., Vittal J. J., Imiyabir Z., Madani L., Khozirah K. S., Goh S. H., J. Nat. Prod., 63, 473-476 (2000).

20) Wang S.-K., Cheng Y.-J., Duh C.-Y., J. Nat. Prod., 64, 92-94 (2001).

21) Shiengthong D., Ungphakorn A., Lewis D. E., Massy-Westropp R. A., Tetrahrdron Lett., 1979, 2247-2250.

22) Purushothaman K. K., Sarada A., Connolly J. D., Akinniyi J. A., J. Chem. Soc., Perkin Trans. 1, 1979, 3171-3174.

23) Inada A., Murata H., Inatomi Y., Nakanishi T., Darnaedi, D., J. Nat. Prod., 58, 1143-1146 (1995).

24) Inada A., Ohtsuki S., Sorano T., Murata H., Inatomi Y., Darnaedi, D., Nakanishi T., Phytochemistry, 45, 379-381 (1997).

25) Based on the reported results, ${ }^{5,13)}$ the correlation peak between $4-\mathrm{H} / 13$ $\mathrm{H}$ and between $21-\mathrm{H} / 2^{\prime \prime}, 6^{\prime \prime}-\mathrm{H}_{2}$ indicated a $13 S$-relative configuration in $\mathbf{1}-\mathbf{3}$ and $\mathbf{8}$.

26) Correlations between $10-\mathrm{H}$ and carbon atoms in $\mathbf{1}$ was obscure due to the overlapping $10-\mathrm{H}$ and $\mathrm{OH}$ proton of $\mathrm{MeOH}-d_{4}$.

27) Correlations between $10-\mathrm{H} / \mathrm{C}-2, \mathrm{C}-3, \mathrm{C}-4$, OCO, between $3-\mathrm{H} / \mathrm{C}-2, \mathrm{C}-$ 4, C-5, C-11, C-1', C-1," and between 4-H/C-3, C-5, C-5a, C-10, C$11, \mathrm{C}-1^{\prime \prime}$ were observed. 